\title{
Perspectivas sobre a terceirização na recria de bezerras leiteiras no
}

\section{oeste catarinense}

\author{
Diego Córdova Cucco ${ }^{1}$, Willian Nardi², Fabricio Pilonetto ${ }^{3}$, Vagner Miranda Portes ${ }^{4}$ e Aline Zampar ${ }^{5}$
}

\begin{abstract}
Resumo - Com o crescimento e a modernização recente da cadeia produtiva do leite no estado, a especialização se torna cada vez mais presente. Com o objetivo de avaliar o interesse de produtores de leite no sistema terceirizado de recria de bezerras, aplicou-se um questionário a 67 produtores de leite de cinco microrregiões do Oeste catarinense. Os dados foram tabulados e discutidos a partir de uma análise descritiva. Concluiu-se que cerca de metade dos produtores aceita o sistema de recria terceirizada. Em geral, os entrevistados têm preferência por animais da raça Holandês, com idade média de 23 meses. Além disso, $85 \%$ dos produtores preferem adquirir animais prenhes.
\end{abstract}

Termos para indexação: bovinocultura leiteira; recria de novilhas; sistema produtivo.

\section{Perspectives on outsourcing dairy cattle breeding in western Santa Catarina}

Abstract - With the recent growth and modernization of milk production chain in Santa Catarina State the specialization becomes more present. A research was carried out with the aim of evaluating the interest of dairy farmers from five Microregions of the West of Santa Catarina State regarding their interest in outsourced system of heifer rearing. A questionnaire was applied to 67 dairy farmers in that area. The data were tabulated and discussed from a descriptive analysis. In conclusion, about half of the producers interviewed accepted the outsourced rearing system. The animals profile wanted are Holstein breed, pregnant, with average of 23 months old. In addition, it is preferable for $85 \%$ of producers to purchase pregnant animals.

Index terms: dairy cattle; rearing heifer; productive systems.

\section{Introdução}

Atualmente a produção mundial de leite se encontra em crescimento. O Brasil segue como o quarto maior produtor mundial de leite (EMPRESA BRASILEIRA DE PESQUISA AGROPECUÁRIA, 2017), e o estado de Santa Catarina está hoje em quarto lugar na produção nacional, que se concentra na região Oeste, responsável por aproximadamente $75 \%$ da produção estadual (EMPRESA BRASILEIRA DE PESQUISA AGROPECUÁRIA, 2017; EMPRESA DE PESQUISA AGROPECUÁRIA E EXTENSÃO RURAL DE SANTA CATARINA, 2018).

Dada a evolução da atividade leiteira e a atual especialização de diferentes elos da cadeia, o sistema de recria terceirizada surge como uma alternativa para reduzir os custos com a produção de bezerras e novilhas e otimizar o tempo dedicado à produção de leite. Silveira et al. (2003) apontaram que os ganhos com o incremento no número de vacas dos rebanhos e com o aumento na produção de leite são maiores, a ponto de pagar o serviço terceirizado, permitindo assim aumentar o retorno econômico das propriedades, porque os fatores de produção são maximizados para as vacas em fase de produção.

De acordo com Katsman (2006), a adoção deste sistema implica na necessidade de menor capital investido pelo produtor, no alto aproveitamento dos fatores de produção existentes para a atividade leiteira e no uso de mão de obra especializada tanto para produção de leite quanto para recria de bezerras. Martins et al. (2014) verificaram que a estrutura de governança desenvolvida pelos centros de recria congrega interesses de agricultores familiares e cooperativas, proporcionando eficiência ao sistema agroindustrial leiteiro onde for adotado. Neste contexto, este sistema pode ter grande inserção em regiões que possuem grande vocação para a atividade leiteira e baseiam-se em pequenas propriedades de cunho familiar, como é o caso da região oeste de Santa Catarina.

O objetivo desta pesquisa foi avaliar o conhecimento e o interesse de produtores de leite do oeste catarinense no sistema terceirizado de recria de bezerras, bem como o perfil de propriedades/produtores e dos animais que possam vir a ser desejados oriundos deste sistema. $\vee$

Recebido em 19/07/2017. Aceito para publicação em 16/05/2018.

http://dx.doi.org/10.22491/RAC.2019.v32n1.1

${ }^{1}$ Médico-veterinário, Dr., Universidade do Estado de Santa Catarina (Udesc/CEO), Rua Beloni Trombeta Zanin, 680-E. Bairro Santo Antônio. CEP: 89815-630.

Chapecó - SC fone: (49) 2049-9561, e-mail: diego.cucco@udesc.br.

${ }^{2}$ Zootecnista, Universidade do Estado de Santa Catarina (Udesc/CEO), e-mail: williannardizoo@gmail.com.

${ }^{3}$ Zootecnista, M. Sc. Universidade do Estado de Santa Catarina (Udesc/CEO), e-mail: fpilonetto@usp.br.

${ }^{4}$ Médico-veterinário, Dr., Epagri/Cepaf, Servidão Ferdinando Tusset, S/N, Bairro São Cristóvão. CEP: 89803-904. Chapecó, SC, fone: (49) 2049-7510, e-mail: vagnerportes@epagri.sc.gov.br.

${ }^{5}$ Zootecnista, Dra., Universidade do Estado de Santa Catarina (Udesc/CEO), e-mail: aline.zampar@udesc.br. 


\section{Metodologia da pesquisa}

Foram selecionados cinco municípios líderes no volume de leite produzido com base em dados de 2015 do Instituto Brasileiro de Geografia e Estatística (2017) nas cinco microrregiões do oeste catarinense (São Miguel do Oeste, Chapecó, Concórdia, Joaçaba e Xanxerê). Os municípios líderes de cada microrregião e o respectivo número de produtores entrevistados foram: Guaraciaba (15); São Lourenço do Oeste (15); Concórdia (12); Videira (13); e Abelardo Luz (12), totalizando 67 propriedades visitadas.

Foi aplicado um questionário dividido em quatro seções. A primeira, para identificar o perfil das propriedades e dos rebanhos (principal fonte de renda, área, mão de obra, sistema de produção, idade e tamanho do rebanho, padrão racial, uso de inseminação artificial, volume de leite produzido e preço do leite). A seção seguinte se propôs avaliar o conhecimento e interesse do produtor na recria terceirizada de novilhas (conhecimento do sistema, credibilidade, modelo de negociação e sistema de pagamento). Caso houvesse interesse pela terceirização da recria, o objetivo da terceira seção era traçar o perfil dos animais (padrão racial, idade, tamanho). Do contrário, se não houvesse interesse por parte do produtor rural, a última seção buscou entender os motivos pelos quais o sistema não era aceito. Após aplicados os questionários, os dados foram tabulados e analisados através de análise descritiva, em que foram calculadas medidas de tendência central e de variabilidade.

\section{Caracterização das}

\section{propriedades entrevistadas}

A Tabela 1 contém o panorama das propriedades e de seus rebanhos. A principal fonte de renda apresentada pelas propriedades foi a bovinocultura de leite, em $84 \%$ dos entrevistados. Em relação a mão de obra destinada à atividade leiteira, em média foram identificadas quatro pessoas por propriedade, sendo que $90 \%$ eram familiares e $10 \%$ contratados.

A área média total das propriedades foi de 34 hectares. A área utilizada para bovinocultura de leite foi de $51 \%$ em relação a área total, com predominância do sistema a pasto com suplementação (86\%) e presença de sistemas intensivos (14\%), como free stall ou compost barn.

Em média, as propriedades possuíam cerca de 60 animais, que foram divididos nas seguintes categorias: bezerras, para animais com até um ano de idade; novilhas, de um ano até o primeiro parto; vacas secas; e vacas em lactação. Campos e Ferreira (2001) recomendam, para compor o rebanho, cerca de $25 \%$ de bezerras, $25 \%$ de novilhas, $8 \%$ de vacas secas e $42 \%$ de vacas em lactação. Neste estudo, os rebanhos eram compostos, na grande maioria, por vacas lactantes (51\%), seguidas de novilhas (21\%), bezerras (16\%) e vacas secas (11\%). Isso denota um bom percentual de vacas em lactação e um potencial de retirar da propriedade cerca de $37 \%$ dos animais para submetê-los a terceirização.

A raça Holandês é predominante entre as propriedades rurais, com $71 \%$ do total de animais, seguida pela raça Jersey, com $18 \%$, e $11 \%$ de outras raças ou cruzamentos. A região de São Miguel do Oeste apresentou os maiores percentuais de animais da raça Jersey (36\%), e a região de Chapecó, os maiores percentuais de animais de outras raças e cruzados (24\%).

Quanto à utilização da inseminação artificial (IA), $87 \%$ dos entrevistados optam por esta biotécnica. Destes, $28 \%$ utilizam mão de obra externa à propriedade para o procedimento. Dentre as propriedades que utilizam IA, em aproximadamente $77 \%$ o sêmen é adquirido pelos proprietários ou por seus prestadores de serviços, e $23 \%$ utilizam sêmen fornecido pelas prefeituras.

$\mathrm{O}$ volume de leite produzido nas propriedades foi de, em média, 530 litros por dia, a produção média por vaca foi aproximadamente de 17 litros diários. A remuneração dos produtores apresentou grandes variações entre as propriedades em decorrência dos métodos de pagamento dos laticínios e da escala produzida, com a média dos preços de $\mathrm{R} \$ 1,31$ (variou de $\mathrm{R} \$ 1,23$ a 1,41 na média de cada microrregião) por litro. As bonificações também foram questionadas, e somente alguns produtores confirmaram receber este tipo de pagamento; dentre estes, a média de bonificação foi de $\mathrm{R} \$ 0,12$, de 17 laticínios diferentes, aos quais entregam o leite.

\section{Perspectivas para recria terceirizada no Oeste catarinense}

A recria terceirizada é uma alternativa disponível aos produtores de leite e pode fazer a cadeia evoluir devido à especialização das atividades. De acordo com Silveira et al. (2003), os produtores envolvidos com o sistema demonstram satisfação com as facilidades de manejo, os ganhos na produção, a produtividade e a rentabilidade da atividade. $O$ autor ainda cita o sistema terceirizado como uma nova oportunidade de renda para algumas propriedades.

O conhecimento do produtor sobre o sistema e seu interesse neste se encontram na Tabela 2. Cerca de $28 \%$ dos produtores afirmam conhecer 0 sistema de recria terceirizada, com as microrregiões de Concórdia e São Miguel do Oeste apresentando o maior índice de respostas positivas. Observamos que apenas $3 \%$ dos produtores entrevistados utilizam atualmente o sistema terceirizado. Foi pedido aos produtores que afirmaram conhecer este sistema que o descrevessem resumidamente, ao que declararam se tratar de um sistema em que o produtor de leite encaminha as bezerras com alguns dias de vida para um recriador especializado e recebe as novilhas na propriedade, um certo tempo antes do parto.

Após o questionamento inicial, foi realizada uma breve explanação para os produtores sobre este sistema, e foi verificado então seu possível interesse na recria terceirizada. No geral, 
aproximadamente $47 \%$ dos produtores responderam positivamente, embora a região de São Miguel do Oeste tenha apresentado o menor percentual, com cerca de 26\% de interessados. Quando questionados sobre a credibilidade no sistema de recria terceirizada, $71 \%$ afirmaram confiar no sistema (Tabela 2).

Aos produtores que não se interessaram pelo sistema foi indagado sobre os motivos pelos quais não aceitavam a terceirização. Grande parte deles não gostaria de inserir animais de outros locais em sua propriedade e preferiam produzir as próprias novilhas. Outros ainda declararam motivos como a falta de sucessão familiar e a dificuldade de adaptação dos animais.

Aos produtores interessados no sistema foram apresentados possíveis modelos de negociação: a troca, em que o produtor entrega um montante de bezerras nascidas para o recriador e recebe uma proporção menor de novilhas, enquanto o restante permanece sob posse do recriador como forma de pagamento do serviço prestado; e o contrato, no qual o produtor entrega todas as bezerras nascidas e recebe as novilhas, serviço este pago mensalmente ou ao final do período, conforme acordado no contrato entre as partes. O sistema de troca teve $73 \%$ da preferência dos produtores (Tabela 3).

Animais da raça Holandês são preferidos por aproximadamente $72 \%$ dos produtores, da raça Jersey por $5 \%$ e de outras raças ou cruzamentos por $23 \%$, principalmente animais oriundos do cruzamento entre Holandês e Jersey. Quanto ao status reprodutivo das novilhas, $87 \%$ dos produtores preferem recebê-las prenhes, sendo que $86 \%$ deles optariam pelo acasalamento de seus animais. A preferência dos produtores em relação a idade e peso das novilhas foi de animais com idade média de 23 meses e peso aproximado de $350 \mathrm{Kg}$, números similares aos recomendados pela Empresa Brasileira de Pesquisa Agropecuária (2006) para novilhas aptas à reprodução. A única característica que difere trata do momento da parição, cujo peso recomendado é superior.

A respeito dos aspectos sanitários, 91\% dos produtores exigiram a aplicação de alguma vacinação, principalmente contra a rinotraqueíte infecciosa bovina (IBR) e as clostridioses, que foram as doenças mais citadas. Outras exigências, feitas por $70 \%$ dos produtores, foram: seguro para os animais, seriedade com o trabalho, cuidados com nutrição e sanidade.

Ao se questionar o valor considerado justo a ser pago por novilhas prenhes, foi obtido uma média de $\mathrm{R} \$ 3.814,29$, sendo $\mathrm{R} \$$ 4.158,86 o máximo que os produtores aceitariam pagar por um animal em tais condições. Para novilhas vazias, o valor médio considerado justo foi de $R \$ 1.950,00$, enquanto o máximo foi de $R \$ 2.000,00$.

Não observamos relação entre a aceitação do sistema como principal fonte de renda da propriedade, sistema de produção, média de área da propriedade, tamanho do rebanho e mão de obra utilizada. Isto demonstra que o sistema pode ser utilizado por diferentes perfis de produtores e em diferentes propriedades.

\section{Considerações finais}

A recria terceirizada possui aceitação em cerca de metade dos produtores pesquisados da região que compõe a maior bacia leiteira de Santa Catarina. Devido ao grande número de produtores de leite na região, pode ser uma atividade viável e com benefícios a todos os elos envolvidos na produção.

O perfil dos animais deste sistema almejado pelos produtores se configura em novilhas da raça Holandês, prenhe, com possibilidade de escolha do acasalamento e 23 meses de idade.

\section{Agradecimentos}

Os autores agradecem a colaboração das Zootecnistas Juliane Taiz Calgaro e Magda Galvão.

\section{Referências}

CAMPOS, A.T.; FERREIRA, A.M. Instrução técnica para o produtor de leite: composição do rebanho e sua importância no manejo. Juiz de Fora: Embrapa Gado de Leite, 2001.

EMPRESA BRASILEIRA DE PESQUISA AGROPECUÁRIA. Reprodução de bovinos leiteiros. Juiz de Fora: Embrapa Gado de Leite, 2006. Disponível em: <https://www. agencia.cnptia.embrapa.br/recursos/ Reprod_AnimID-ZXT4FtLDun.pdf>. Acesso em: 18 jul. 2017.

EMPRESA BRASILEIRA DE PESQUISA AGROPECUÁRIA. Indicadores: leite e derivados. Juiz de fora: Embrapa Gado de Leite, v.8, n.69, 2017. Disponível em: <http:// ainfo.cnptia.embrapa.br/digital/bitstream/ item/167783/1/Cnpgl-2017-IndicadoresLeite-69.pdf>. Acesso em: 18 jul. 2017.

EMPRESA DE PESQUISA AGROPECUÁRIA E EXTENSÃO RURAL DE SANTA CATARINA. Números da agropecuária catarinense: 2018. Florianópolis: Epagri, 2018.

INSTITUTO BRASILEIRO DE GEOGRAFIA E ESTATÍSTICA. IBGE cidades: pecuária, leite de vaca, produção, quantidade. Rio de Janeiro: IBGE, [201-]. Disponível em: <http://www. cidades.ibge.gov.br/xtras/uf.php?lang $=\& c$ oduf $=42 \&$ search=santa-catarina $>$. Acesso em: 10 mar. 2017.

KATSMAN, T.J. Terceirização de serviços. In: SIMPÓSIO DE BOVINOCULTURA DE LEITE, 2., 2006, Chapecó. Anais... Chapecó: Núcleo Oeste de Médicos Veterinários, 2006. p.3940.

MARTINS, H.H.; FERREIRA, J.D.; ORLANDI, T.; ROCHA JUNIOR, W.F. Atividade leiteira na agricultura familiar: a terceirização do centro de recria. In: CONGRESSO DA SOCIEDADE BRASILEIRA DE SISTEMAS DE PRODUÇÃO, 10., 2014, Foz do Iguaçu. Anais... [S.I]: SBSP, 2014. p.1-5

SILVEIRA, V.C.P.; RIBEIRO, C.M.; PORTELA, J.S.; AMARAL, L.C.; SUÑE, R.; BAIER, C.H. Estudo de caso da adoção da recria terceirizada de terneiras leiteiras numa propriedade em Hulha Negra, RS: impactos e perspectivas. In: CONGRESSO BRASILEIRO DE ECONOMIA E SOCIOLOGIA RURAL, 41., 2003, Juiz de Fora. Anais... Brasília, DF: Sober, 2003. 